\title{
UMA INVESTIGAÇÃO SOBRE A ORIGEM DA HERMENÊUTICA NA TERCEIRA CRÍTICA
}

\author{
Jaci Rene Costa Garcia*
}

RESUMO: Tendo como objetivo geral investigar o papel da estética kantiana para a hermenêutica, a delimitação do estudo envolve: [i] uma abordagem filosófica unificada pelo sistema crítico kantiano capaz de identificar os pressupostos que permita a realização dos julgamentos, [ii] o lugar do humano na comunidade e [iii] as possibilidades de uma orientação hermenêutica reflexionante. Como método, utilizou-se o dedutivo, considerando-se a orientação da pesquisa a partir de conceitos originalmente kantianos.

Palavras-chaves: Direito. Hermenêutica. Filosofia. Estética. Kant.

\section{AN INVESTIGATION ABOUT THE ORIGIN OF HERMENEUTICS IN THE THIRD CRITIQUE}

ABSTRACT: Since the aim of research is to investigate the role of Kantian aesthetics for the hermeneutics, the delimitation of the study involves: [i] an unified philosophical approach by the Kant's critical system which is able to identify the assumptions that allow the realization of judgments, [ii] the place of the human in the community and [iii] the possibilities of a reflective hermeneutics orientation. It was used the deductive method, considering the research orientation from originally Kantian concepts.

Key-words: Law. Hermeneutics. Philosophy. Aesthetics. Kant.

\section{INTRODUÇÃO}

Pretende-se investigar a hipótese de que há uma hermenêutica desde Kant ${ }^{1}$. De se registrar: uma hermenêutica democrática, que respeita a alteridade e alerta para a falibilidade inerente a uma ausência de dominação prévia pelos conceitos, potencializando a responsabilidadade ética a partir de um conhecimento que sempre será construído e validado em comunidade. Nesse contexto, a pesquisa considera que o domínio da faculdade de julgar (estética) se abstém da determinação do conceito construído a partir das categorias do entendimento e, também, de quaisquer dogmas produzidos no âmbito das crenças. Não existem determinações transcendentais ou autoridades transcendentes. Surge, originalmente, o lugar da hermenêutica na filosofia kantiana. A estética é o lugar da construção comunitária do saber. A estética é o lugar da hermenêutica.

\footnotetext{
* Mestre em Filosofia (UFSM), Doutor em Direito Público (UNISINOS) e Pós-Doutor em Filosofia. Professor do Curso de Direito da Universidade Franciscana (UFN), e-mail garcia@ufn.edu.pro.br

${ }^{1}$ As citações das obras de Kant correspondem à forma recomendada pela Akademie-Ausgabe e adotada pela Sociedade Kant Brasileira.

CONPEDI LAW REVIEW | EVENTO VIRTUAL | v. 7 | n. 2 | p. 76 - 96 | JUL - DEZ | 2021 
A pesquisa ganha em relevância quando se vive num cenário/momento em que há uma multiplicidade de normas e de teorias sobre normas que geram um indeterminismo em duplo sentido: indeterminismo epistemológico, afetando a capacidade de predição, ou seja, talvez não seja possível predizer a realidade em que o fenômeno jurídico se situa; indeterminismo ontológico/metafísico, no momento em que percebemos o alto grau de indeterminação da realidade, sendo impossível normatizar previamente (predizer) todas as situações que se apresentam. Nesse cenário, a investigação da hermenêutica desde a estética traz a possibilidade de refletir sobre a produção de julgamentos oferecerem uma resposta - ao menos provisória - ao campo epistemológico com reflexos no campo do fenômeno jurídico.

Concebe-se o juízo estético no sistema kantiano com uma função hermenêutica de mediação entre entendimento e razão, resultando numa orientação: não se trata de indução e nem dedução, as faculdades estão num "livre jogo, porque nenhum conceito determinado limita-as a uma regra de conhecimento particular" (KU, $\left.\S 9^{\circ}\right)$, podendo-se dizer que o livre jogo das faculdades da imaginação e do entendimento é que permitirão uma compreensão interpretativa que tem na base um sentimento estético (estética da liberdade) correlato ao sentimento de vida.

Importante o registro desde o momento introdutório da pesquisa, que a questão do sentimento de diferença que Kant (WDO) traz como essencial ao processo de orientação também é objeto da reflexão heideggeriana em Ser e Tempo (HEIDEGGER, 2012, p. 319321), explorando a questão que parte da afirmação kantiana de que o sentimento de esquerdo/direito, por exemplo, é o que permite que o nosso movimento num quarto escuro, ao lado de um conhecimento prévio de algum móvel disposto em tal ambiente. A orientação que possibilita que se atinja um determinado fim proposto passa a ser guiado pelo sentimento de diferença previamente internalizado.

Forte nessa referência ao texto kantiano, Heidegger irá dizer que Kant quis mostrar unicamente que toda orientação requer um princípio subjetivo, tornando ácida a crítica endereçada ao filósofo de Königsberg quando diz que o "a priori de ser direcionado para a direita e para a esquerda se fundamenta, contudo, no a priori subjetivo do ser-no-mundo, que não tem nada a ver com uma determinidade de antemão limitada de um sujeito falto-demundo" (HEIDEGGER, 2012, p. 321, grifo do autor). O que se identifica é que Heidegger interpreta o sujeito kantiano pela metade, esquecendo-se da dimensão pragmática e estética da 
filosofia kantiana, capazes de recolocar o ser no mundo, onde a subjetividade e a racionalidade já estariam enraizadas na temporalidade ${ }^{2}$.

Dessa forma, intencionalmente, a pesquisa desvia-se da interpretação apenas "determinante" de um sujeito desconectado do mundo, tal qual a apresentada por Heidegger e que sintetiza boa parte do pensamento de um universo de críticos da filosofia kantiana, servindo de diferença para aclarar o propósito da investigação. Parte-se para olhar Kant a partir de uma perspectiva epistemológica presente no criticismo, conectando a filosofia ao mundo e com capacidade de localizar o humano espaço-temporalmente.

Importante registrar a filiação da pesquisa a uma interpretação não dogmática de Kant. Alinha-se à pesquisa ao pensamento de Conill Sancho (2010) que, na mesma linha de Makkreel, defende a possibilidade de uma crítica da razão hermenêutica a partir da estética, permitindo um olhar mais abrangente do sistema filosófico kantiano. Identifica Conill Sancho que há um potencial inexplorado por Gadamer na Antropologia de um ponto de vista pragmático e na Crítica da faculdade de julgar, obras que envolvem uma estética e uma pragmática da liberdade, ambas essenciais ao trato de uma hermenêutica crítica com implicações éticas.

\section{ALGUMAS CONSIDERAÇÕES SOBRE UMA HERMENÊUTICA DESDE KANT}

Gadamer chama a atenção para a subjetividade presente no juízo estético, aguçando a necessidade de tomada de consciência do cuidado que se deve ter quando se propõe qualquer avanço tomando por base um sistema altamente complexo como a filosofia kantiana, sendo apropriado referir Hamm (2000, p. 51) quando repete Kant ao afirmar que "não pode haver um conceito constitutivo para o belo", em face de que a teoria do juízo estético se encontra assentada na experiência estética e, dessa forma, "implica necessariamente a renúncia - aliás, uma renúncia deliberada - tanto a uma ideia de obra enquanto 'possuidora' ou 'geradora' de verdade, como a qualquer dominação da arte por conceitos em geral”. (HAMM, 2000, p. 51).

Essa questão da impossibilidade da verdade alcança em Gadamer uma extensão maior que será fundadora da sua hermenêutica que também não se deixa dominar pelo conceito (embora não renuncie à verdade), especificamente quando diz que o ponto de partida da teoria hermenêutica que postula é a obra de arte, entendendo que a arte se constitui numa "provocação para nossa

\footnotetext{
${ }^{2}$ Embora não seja objeto de análise, importante que se diga que a hermenêutica crítica pode ser compatível com a expressão "o caminho se faz ao caminhar", apenas não abre mão da "ferramenta" que acompanha o homem na sua caminhada: a razão (e os juízos reflexionantes) que orientam o homem no tempo/espaço. 
compreensão porque se subtrai sempre de novo às nossas interpretações e se opõe com uma resistência insuperável a ser transposta para a identidade do conceito" (GADAMER, 2012, p. 37). Tal questão se encontra em Kant que entende a arte como "não dominada conceitualmente", porém não exclui a possibilidade de emissão de juízos e a comunicabilidade.

Conill Sancho voltando-se para Gadamer diz: “os conceitos básicos do humanismo que expõe Gadamer em Verdade e Método (formação, sentido comum, capacidade de juízo e gosto) tem um ineludível sentido ético e não estão desvinculados do horizonte kantiano". (CONILL SANCHO, 2010, p. 64). Ao fazer tal afirmação identifica que não foram aproveitadas por Gadamer questões da Metafísica dos Costumes, da Antropologia de um ponto de vista pragmático e da Crítica da faculdade de julgar, obras que permitem que se encontre o lugar da estética e da pragmática da liberdade na filosofia kantiana, com especial atenção ao sentimento moral e ao problema da aplicação.

Embora uma análise da filosofia crítica permita que se aceite a limitação presente na terceira crítica ao juízo do gosto como defendeu Gadamer, entende-se (com Makkreel e Conill Sancho) que olhar o juízo reflexionante e as questões que envolvem o ato de julgar pode permitir um recomeço da hermenêutica, relacionada a uma epistemologia (criticismo). Ademais, reconhecendo as possibilidades e as limitações inerentes a uma "não dominação" prévia pelos conceitos, revela-se, prima facie, uma vocação construtivista em termos de produção de conhecimento compartilhável.

Nesse sentido, a faculdade da imaginação é mais uma chave de leitura de um Kant hermeneutizável. Numa definição de Vaysse é uma faculdade essencial na constituição da objetividade, apontando que "Hegel vê na imaginação kantiana a unidade originária anterior à cisão sujeito-objeto, e Heidegger, uma lucidez única na filosofia, que consiste em enraizar a racionalidade na temporalidade e na finitude, antecipando assim a questão de ser e tempo." (VAYSSE, 2012, p. 44).

Outro aspecto que assegura uma relação entre Kant e a hermenêutica é o processo interacional com a vida. Nessa linha, há de se marcar que em Kant a relação com a vida é dada pelo sentimento de vida (Lebensgefühl) que - para além de permitir uma relação de continuidade entre Kant e a hermenêutica futura (Dilthey, por exemplo) - apresenta-se como uma verdade elementar, apontando Schmidt (2001) que nossa compreensão do original e mais profundo senso de verdade necessita começar por esse sentimento (feeling of life).

Conill Sancho também irá identificar que o sentimento da vida - interpretado moralmente - poderia ser considerado a manifestação estética da liberdade transcendental, 
trazendo como correlato o sentimento de respeito como manifestação estética da consciência racional da lei moral. Nesse sentido, em Kant a existência pode ser sentida e, embora a existência não possa ser conceituada, não se pode afastar a sua anterioridade e sua relação original com o sentimento. Nessa perspectiva, reflete sobre uma relação de continuidade entre Kant e Dilthey, pois para Conill Sancho a obra kantiana já anuncia uma incipiente filosofia da vida, porque acreditava que a vida somente poderia ser sentida, mas não poderia ser conhecida. Kant e Dilthey concordam que a vida é primordialmente acessível através do sentimento e, conclui Conill Sancho, [i] que o uso kantiano do conceito de vida na Crítica do Juízo demonstra a relação de continuidade com a obra Crítica da razão histórica de Dilthey e [ii] a filosofia da vida em Dilthey busca a autorreflexão (selbstbesinnung) histórica, devendo ser considerada como uma ampliação do princípio do juízo reflexionante kantiano.

Percebe-se que a Hermenêutica em Dilthey assume certo psiquismo e a faculdade da imaginação passa a ser um acesso privilegiado quando as vivências passam a integrar a possibilidade de compreensão do mundo, sendo que a tarefa de compreensão é definida como um "[...] transpor-se para o interior de, seja para o interior de um homem ou de uma obra". (DILTHEY, 2010, p. 196). Na perspectiva de Dilthey o compreender é um "transporte do próprio si mesmo para o interior da quintessência dada de manifestação de vida [...] Um covivenciar pleno está ligado ao fato de a compreensão prosseguir na linha do próprio acontecimento". (DILTHEY, 2010, p. 197).

Seguindo o filósofo, conceitos como transposição, reprodução de imagens e revivências vão enlaçando a possibilidade de compreensão que criam um "vasto reino de possibilidades que não estão presentes na determinação de sua vida real efetiva". (DILTHEY, 2010, p. 198). A hermenêutica, nessa breve análise de Dilthey, parece que abre em infinitas possibilidades a interpretação, porém, ao analisar a estética musical, o que parece aleatório possui internamente uma vivência que se acomoda na associação de notas que compõe a obra, em outras palavras, no valor estético do belo. (DILTHEY, 2010, p. 207-212).

$\mathrm{Na}$ análise da música, irá dizer que o elo anterior condiciona o posterior e, ainda, na última nota a primeira encontra o seu fundamento e, mesmo entendendo que são múltiplas as possibilidades no ato de composição, irá dizer

[...] em algum lugar nesse condicionamento há uma necessidade [...] esse precisar-ser-assim não é uma necessidade, mas a realização de um valor estético; e não há dúvida de que, em uma determinada posição, aquilo que 
segue não poderia ter se dado de outro modo. (DILTHEY, 2010, p. 2072012).

Inabstante a evidente distinção entre o juízo lógico e o juízo do gosto $(\mathrm{KU}, \S 35)$ - o que é plenamente aceitável por Dilthey, a hermenêutica em Dilthey se apropria do juízo estético no qual o belo surge no momento de êxtase que se evidencia na expressão "não poderia ter se dado de outro modo", o que vale dizer que na base da hermenêutica de Dilthey a reflexão estética assume notas importantes que irão permitir a abertura interpretativa ao campo infinito das possibilidades e, ao mesmo tempo e não de forma paradoxal, emerge um condicionamento que permite o ato da compreensão dos casos que se apresentam (como se estivessem em jogo diante - e também no interior - do intérprete a finalidade e a causalidade).

Com as considerações, demonstra-se que Dilthey dialoga fortemente com Kant, especialmente quando este último aponta que a obra de arte possui uma ideia de totalidade análoga à de um ser vivo, defendendo que a causalidade na imaginação pode ser recíproca, aceitando até mesmo a inversão causal ${ }^{3}$, ao afirmar

\begin{abstract}
A ligação causal, na medida em que ela é simplesmente pensada mediante o entendimento, é uma conexão que constitui uma série (de causas e efeitos) que vai sempre no sentido descendente; [...] Porém também se pode, em sentido contrário, pensar uma ligação causal segundo um conceito da razão (de fins), ligação que se a considerarmos como uma série, conteria tanto no sentido descendente, como no ascendente uma forma de dependência, na qual a coisa, que uma vez foi assinalada como efeito, passa então no sentido ascendente a merecer o nome de uma causa daquela coisa de que ela fora o efeito. No domínio prático (nomeadamente no da arte) encontra-se facilmente uma conexão semelhante [...]. (KU, § 65, p. 289).
\end{abstract}

Nessa linha, apropriada a relação proposta entre Kant e Dilthey por Conill Sancho com o objetivo de sustentar a hermeneutização de Kant, tendo como fio condutor a estética e a pragmática kantianas, realizando-se uma passagem pela filosofia de Dilthey apenas com o intuito de demonstrar a sua vinculação com a estética e com o sentimento de vida (questões já assumidas pela filosofia kantiana).

A grande questão de Conill Sancho é descobrir a mediação entre hermenêutica (condicionalidade, historicidade) e a filosofia crítica (incondicionalidade, universalidade), para compreender uma razão prática, condicionada historicamente e capaz de princípios éticos incondicionados, em outras palavras, a possibilidade de validade de uma universalização

\footnotetext{
${ }^{3}$ A inversão causal encontrada na estética sob a forma de "dependência no sentido ascendente", tanto em Kant quanto em Dilthey, terão reflexos importantes na estrutura epistemológica da hermenêutica.
} 
impura (histórica e prática, portanto). Cita a proposta de Wellmer (CONILL SANCHO, 2010, p. 213), que defende que uma lei ética incondicionada, como o imperativo categórico de Kant, não necessita ser pensada como um "fato da razão", mas deve ser pensada como "fato de uma vida sob condições da razão", sendo suficiente que se mostre como um modo histórico de vida governado pela razão. Conill Sancho (2010) arrasta a temporalidade do ser para a temporalidade da razão, unindo ser, logos, sentimento de vida, permitindo que se postule um universalismo hermenêutico.

Tal universalismo é possível de ser prospectado pela concepção de sensus communis ao lado do potencial pragmático do juízo reflexionante, anotando Conill Sancho ${ }^{4}$ (2010, p. 68) que o sentido de justiça integra o sentido comum e é essencial para a convivência, estando presente ao longo de toda a trajetória da filosofia prática, desde Aristóteles até Rawls, passando pela Crítica da faculdade de julgar kantiana.

Assim, a hermenêutica como postulada por Conill Sancho (2010, p. 192), vai se caracterizar como uma epistemologia que se nutre de uma vontade de compreensão que, em muitos aspectos, também encontra a filosofia de Gadamer, aprendendo a ver o outro em sua possível razão e a duvidar da razão própria, questões que permitem um exercício de "não dominação" e de resistência ao domínio do caráter instrumental da razão, ao que Conill Sancho denomina "vontade de domínio". A ética hermenêutica crítica, nesse sentido, reconhece que [i] o outro pode ter razão, [ii] a vontade de domínio deve deter-se em face do outro, [iii] deve-se respeitar o outro de forma que possa se obter a participação de todos, reconhecendo Conill Sancho que a ética aplicada é o campo onde pode se desenvolver uma forma de compreensão hermenêutica, trazendo como exemplos "o diálogo, a escuta, a mediação entre condicionalidade e incondicionalidade na prática concreta, o exercício da capacidade de julgar, a deliberação, a eleição e a decisão" (CONILL SANCHO, 2010, p. 195).

\footnotetext{
${ }^{4}$ Segundo Conill Sancho (2010, p. 68), Gadamer novamente é omisso em relação ao pensamento kantiano, pois ao tratar de sensus communis retoma o conceito a partir de Aristóteles e, citando Vico, traz que o sensus communis é o sentido do justo e do bem comum presente em todos os homens, um sentido que se adquire através da comunidade da vida.
} 


\section{SITUANDO A HERMENÊUTICA NA FILOSOFIA KANTIANA ${ }^{5}$ : O MODO DE OPERAR DOS JUÍZOS REFLEXIONANTES}

Em sede da filosofia racionalista kantiana, realiza-se uma análise do juízo reflexionante e do percurso para a construção de uma hermenêutica crítica, encontrando-se um ambiente favorável ao trato da Hermenêutica a partir de Kant, quando Makkreel propõe uma "Theory of reflective interpretation" (Imagination and Interpretation in Kant, 1990). Na obra Imaginação e Interpretação em Kant, Makkreel propõe uma vinculação da filosofia transcendental à hermenêutica, tratando da imaginação e do seu papel na interpretação, argumentando contra a noção comumente aceita de que a filosofia transcendental de Kant é incompatível com a hermenêutica. A acusação de que a filosofia transcendental de Kant é inadequada à tarefa de interpretação pode ser afastada, no entendimento de Makkreel, quando se analisa o papel da imaginação no conjunto da obra kantiana.

Para tornar mais clara a defesa de Makkreel, identifica-se no conjunto da obra kantiana dois tipos de juízos que implicam sempre várias faculdades e exprimem o ajuste destas faculdades entre si, denominados determinantes e reflexionantes. O juízo determinante é aquele que exprime o acordo das faculdades sob uma faculdade totalizante/hegemônica, como o entendimento na KrV (Crítica da Razão Pura) e a razão na KrP (Crítica da Razão Prática). Por sua vez, o juízo reflexionante exprime um livre jogo entre todas as faculdades, sendo objeto da terceira crítica (KU - Crítica da Faculdade de Julgar), um juízo que representa a conformidade a fins de um determinado objeto, podendo-se dizer que a faculdade da imaginação (como faculdade das intuições a priori) dialoga como o entendimento (faculdade dos conceitos), num movimento que permite que objeto refletido possa ser considerado como conforme a fins $e$ correlato do sentimento de prazer ${ }^{6}$.

A respeito do processo reflexionante, Irá dizer Kant que "o objeto chama-se então belo e a faculdade de julgar mediante tal prazer (por conseguinte também universalmente válido) chama-se gosto" (KU, XLV). Mesmo guardando um caráter contigente dada a diversidade de sujeitos afetados, Kant chama a atenção para o fato de que "as condições dessa reflexão são válidas a priori de forma universal” (KU, XLV). Afirma, então, que a faculdade de juízo

\footnotetext{
${ }^{5}$ Utilizando a metáfora caá-açapaba, os juízos reflexionantes representam a abertura na floresta, uma possibilidade de sentir e existir conjuntamente numa clareira na floresta. Algo que se abre [...]

${ }^{6}$ Ao longo da exposição, em diversos momentos e sob a orientação da filosofia kantiana, sentimento de prazer será identificado como sentimento de vida que é o móbil que está na origem da hermenêutica crítica. 
estética $^{7}$ é por isso "uma faculdade de ajuizar uma coisa segundo uma regra, mas não segundo conceitos [...]" (KU, LII), não exprimindo um domínio do objeto sob uma faculdade determinante, mas um acordo livre de todas as faculdades a propósito de um objeto refletido numa determinda circunstância espaço-temporal e sob a regência de regras do entendimento que permitem um processo compreensivo que transcende a esfera individual, necessitando da reciprocidade inerente ao processo de construção compartilhada.

Embora os juízos reflexionantes integrem o sistema kantiano, os juízos determinantes encetados pelas categorias do entendimento - sempre foram o ponto de partida dos estudiosos para a compreensão do sistema crítico kantiano, apagando-se a estética (sensibilidade) o que acabou por enfraquecer o papel na ampliação do conhecimento.

Como ilustração, a conhecida história do Ornitorrinco de Umberto Eco (ECO, 2002) parece providencial nesse momento por dois motivos: primeiro, pela redução simplificadora da proposta; segundo, pela clareza que surge na crítica ao racionalismo kantiano, especialmente porque o autor italiano procura testar e provar a insuficiência da cognição a partir do esquematismo kantiano.

Em Kant e o Ornitorrinco, Eco irá questionar os pressupostos e os limites da cognição esquemática, ou seja, aquela que parte de conceitos prontos para vestir a realidade como se tudo estivesse preestabelecido, elegendo Kant como filósofo "conceito" para legitimar a crítica. O ornitorrinco pela "natureza transgressora" passa a ser o modelo para demonstrar que o "empírico" se debela da regularidade do conceito que tudo pretende determinar ${ }^{8}$. Não é pretensão elaborar uma crítica a Eco (inúmeras já foram realizadas), mas demonstrar que a crítica que o autor elabora reduz o pensamento kantiano ao conceito de juízos determinantes, esquecendo-se de uma parte significativa da filosofia kantiana, ou seja, Kant não é o que diz Eco (talvez a interpretação de Eco tenha transformado Kant num Ornitorrinco), e a abrupta simplificação esquece a "outra metade" que implica em estudar o potencial cognitivo

\footnotetext{
${ }^{7}$ Propor uma abordagem hermenêutica a partir da estética não representa qualquer novidade. O próprio Gadamer diz que a obra de arte foi o ponto de partida da sua teoria hermenêutica, entendendo que a arte se constitui numa "provocação para nossa compreensão porque se subtrai sempre de novo às nossas interpretações e se opõe com uma resistência insuperável a ser transposta para a identidade do conceito". (GADAMER, 2012, p. 37). A pretensão de novidade está em realizar a abordagem a partir da estética kantiana, algo que Gadamer não fez por entender que a estética kantiana incorre em desvios subjetivos que não se prestam a oferecer um modelo para o pensamento hermenêutico.

${ }^{8} \mathrm{O}$ estranhamento no direito não é diferente, inúmeras vezes situações empíricas se apresentam sem uma norma antecedente que possa dar conta da situação nova, exigindo do intérprete uma postura análoga àquela descrita por Eco. O que a pesquisa quer demonstrar é que - diferente do que Eco preconiza - em Kant já é possível uma resposta a partir da hermeneutização do juízo estético.
}

CONPEDI LAW REVIEW | EVENTO VIRTUAL | v. 7 | n. 2 | p. 76 - 96 | JUL - DEZ | 2021 
existente nos juízos reflexionantes ${ }^{9}$ desenvolvidos a partir do juízo estético e teleológico na terceira crítica.

Deixando mais evidente o trato parcial, registram-se as características comuns ao juízo estético e ao juízo teleológico: esses juízos não são determinantes, isto é, eles não representam uma subsunção de um dado a uma regra, na forma de uma operação esquemática da imaginação em que a subjetividade reúne entendimento e sensibilidade, ligando assim o universal ao singular; se constituem como juízos que partem da realidade em sua singularidade e buscam extrair uma regra universal, caracterizando a definição de juízos reflexionantes. Assim, a reflexão é um processo inverso àquele que caracteriza o esquematismo transcendental. Reitera-se, então, que por esquematismo transcendental é o procedimento da imaginação que parte de um conceito universal e chega a sua imagem particular. O reflexionamento, ao contrário, é o procedimento do espírito que procura no que é particular (imagem) sua significação universal (seu conceito).

Para demonstrar alguns problemas e, de forma concomitante, apresentar - ainda de forma incipiente - um Kant hermeneutizável, há de se retomar a distinção entre a faculdade judicativa determinante e a faculdade judicativa reflexionante, trazendo a distinção mais dura presente na Lógica quando Kant diz

A faculdade judicativa (Urtheilskraft) é dúplice: ou faculdade judicativa determinante (bestimmende) ou faculdade judicativa refletente (reflectirende). A primeira vai do universal ao particular (Allgemeinen zum Besondern); a segunda, do particular ao universal. Esta só tem validade subjetiva, pois o universal para o qual ela progride, a partir do particular, é apenas uma generalidade empírica (empirische Allgemeinheit) - um mero análogo (Analogon) da universalidade lógica (logischen Allgemeinheit). $(\log$, AK 132, § 81)

Com a citação restam claras as duas funções da faculdade de julgar, nas palavras de Rohden, V. (2009, p. 3): "uma consiste em determinar, subsumindo o particular sob o universal dado; e a outra, em refletir, isto é, em comparar representações empíricas em vista

\footnotetext{
${ }^{9}$ Tais juízos são a condição para a unificação das faculdades que restará inconteste na terceira crítica. Tal juízo envolve os procedimentos esquemáticos que dão sentido às idéias e aos conceitos na filosofia kantiana e - como o trabalho defende - estão na base da hermenêutica derivada do criticismo. O conceito de esquematismo em Kant é plural e aparece tanto na primeira crítica (esquematismo puro do entendimento), mas também como simbolização (através de analogias) e como metáfora. O direito é um campo plural (lugar comum) que permite a significação dos sentidos a partir de um esquematismo analógico que tem como ponto de partida a terceira crítica. A segunda parte do trabalho propõe apresentar uma teoria do direito que utiliza tal esquematismo. No Brasil, Zeljko Loparic apresenta uma interpretação que sustenta o "esquematismo alargado" na obra "A Semântica transcendental de Kant", bem como filósofo português, Leonel Ribeiro dos Santos, na obra "As metáforas da razão".
} 
de um universal não dado", sendo que as reflexões estéticas e teleológicas estão ligadas a faculdade de julgar reflexionante ${ }^{10}$.

Com a diferença estabelecida, constata-se que o juízo reflexionante ao progredir do particular ao universal, produz duas espécies de ilações: uma por indução e outra por analogia. Kant (Log, p. 133) irá dizer que a indução atua segundo o princípio da generalização, apontando que o conveniente a muitas coisas de um gênero também seria conveniente às restantes dele. Sobre a analogia, irá dizer que opera sob o princípio da especificação, ou seja, as notas concordantes que conhecemos de alguns indivíduos de um gênero podem concordar com outras notas de indivíduos desse gênero. Numa simplificação do próprio Kant "um em muitos, logo em todos: indução; muitos em um (que estão também em um outro): analogia." (Log, p. 133).

O problema a ser enfrentado no presente ponto está suficientemente conformado quando se verifica que tanto a indução quanto a analogia permitem ilações empíricas não universalizáveis (apenas generalizáveis), gerando um déficit em termos de conhecimento nos moldes fornecidos pelos juízos determinantes, a ponto de Kant advertir que essas ilações empíricas são presunções lógicas, não sendo ilações da razão por não estarem sob a categoria da necessidade. Válido dizer que as ausências de universalidade e de necessidade ${ }^{11}$ se apresentam como um óbice ao conhecimento objetivo, embora reconheça que a indução e a analogia são úteis e indispensáveis à ampliação do nosso conhecimento da experiência, recomendando apenas prudência e cautela na sua utilização ${ }^{12}$.

\section{O GEMÜT E E A POSSIBILIDADE DE COMPREENSÃO}

\footnotetext{
${ }^{10}$ Não é objetivo do trabalho transpor a questão filosófica para estudos cognitivos, mas para exemplificar a atualidade da questão, vale citar Piaget quando, sob influência kantiana, diz que "A abstração reflexionante é a retirada, pelo sujeito, das qualidades da coordenação de suas ações. É um processo que procede das ações ou operações dos sujeitos, remetendo para um plano superior o que foi retirado de um nível inferior de atividade. A partir disto leva para composições novas e generalizadoras. [...] a abstração "reflexionante" [...] apoia-se sobre as coordenações das ações do sujeito, podendo estas coordenações, e o próprio processo reflexionante, permanecerem inconscientes, ou dar lugar a tomadas de consciência e conceituações variadas. (PIAGET, 1995, p. 274).

${ }^{11}$ Estes dois juízos que envolvem o universal (totalidade) e o necessário (apodítico) são epeistemologicamente relevantes e fortemente presentes nos juízos determinantes. A intenção da pesquisa - além de estabelecer a relação da hermenêutica com os juízos reflexivos - e de como estes resolvem a sua relação com a necessidade e a universalidade.

${ }^{12}$ É de se recordar que se faz a defesa de que a hermenêutica se caracteriza epistemologicamente pelo envio de juízos estéticos a juízos cognitivos, já se encontrando na definição kantiana dos juízos reflexionantes um ganho na medida em que aponta para uma extensão do conhecimento e, pari assu, um prejuízo em termos de precisão estando a indicar um possível limite. A pesquisa - na proporção que se desenvolve - pretende aprofundar o exame dessas questões.
} 
Antes de demonstrar a presença do Gemüt como possibilidade unificadora, há de se percorrer brevente a definição colhida no trato da expressão laborado por Rhoden, V. (KU, rodapé 20), apontando que o próprio Kant escolhe Gemüt preferencialmente ao termo Seele (anima) pela sua neutralidade face ao sentido metafísico que o último remete. Os termos latinos animos e mens seriam termos equivalentes, mas Rohden, V. inclina-se a traduzir por ânimo, trazendo a possibilidade de unir Geist (gênio) ao Müt que também carrega o sentido estético de vida. Na seqüencia de seu estudo filológico do termo, Rohden, V. (KU) diz que o termo "mиot" (antigo alto alemão - ahd) significou a faculdade do pensar, querer e sentir e o prefixo " $g e$ " funciona como partícula integradora que remete às partes de um todo, inferindo que Gemüt tenha esse sentido originário de totalidade das faculdades.

Sobre a expressão ${ }^{13}$, encontra-se uma relação do juízo reflexionante com o Geist na Antropologia (Anth, $\S 67,241$ ), afirmando o filósofo que o juízo do gosto é tanto um juízo estético quanto um juízo do entendimento, devendo ser pensado no vínculo entre ambos. Com isso, o juízo reflexionante modera e limita o momento de vivificação do Geist ${ }^{14}$, uma vez que no juízo reflexionante o jogo livre da imaginação não deve colidir com as regras do entendimento. $\mathrm{O}$ que se colhe na Antropologia vem ao encontro da unidade sintetizadora do Gemüt, ou seja, a vivificação é compreendida pelo juízo reflexionante (unidade das faculdades em jogo) e não implica uma oposição aos juízos determinantes.

$\mathrm{Na} \mathrm{KrV}$ a presença unificadora do Gemüt resta presente na seguinte passagem

O nosso conhecimento provém de duas fontes fundamentais do espírito, das quais a primeira consiste em receber as representações (a receptividade das impressões) e a segunda é a capacidade de conhecer um objeto mediante estas representações (espontaneidade dos conceitos); pela primeira é-nos dado um objeto; pela segunda é pensado em relação com aquela representação (como simples determinação do espírito). (KrV, A 50/B 74).

As duas fontes fundamentais (os troncos referidos por Kant) possuem uma ligação com a raiz que pode ser descrito como as determinações do vivido, isto é, o Gemüit ${ }^{15}$ capaz de realizar a ponte no sistema crítico kantiano e que já dá os primeiros sinais na $\mathrm{KrV}$.

Sobre a questão, Rohden, V. (2009, p. 10) afirma que o

\footnotetext{
${ }^{13}$ Foi fundamental ao desenvolvimento do presente capítulo o estudo criterioso levado a termo por de Valerio Rohden denominado "A função transcendental do Gemüt na Crítica da razão pura”. (ROHDEN, V., 2009).

${ }^{14}$ Definido por Kant como "o princípio vivificador no ser humano". (Anth, § 57).

${ }^{15}$ Como já referido, em respeito à tradução portuguesa utilizada restou mantida a expressão espírito que, registra-se que na presente pesquisa optou-se pela tradução por ânimo, forte no acolhimento do estudo de Valério Rohden sobre a expressão original Gemüt.
}

CONPEDI LAW REVIEW | EVENTO VIRTUAL | v. 7 | n. 2 | p. 76 - 96 | JUL - DEZ | 2021 
[...] ânimo seria esse elemento comum às duas fontes, da receptividade e da espontaneidade [...] ter-se-ia de admitir certa unidade originante e enfim um todo, ao qual essas fontes do conhecimento se destinam e com vistas ao qual se articulam.

Ingressando na primeira crítica, é possível extrair uma nova citação em que Kant propõe uma analogia do conhecimento a uma árvore, dizendo que "há dois troncos do conhecimento humano, porventura oriundos de uma raiz comum, mas para nós desconhecida, que são a sensibilidade e o entendimento" ( $\mathrm{KrV}$, B 29), em que a expressão "raiz comum" contém a ideia de unidade de uma totalidade das faculdades (Ge-Müt).

Também na Antropologia Kant vai tratar da afinadade entre as faculdades remetendo a uma ação recíproca entre elas e considerando que, embora heterogêneas, "entendimento e sensibilidade se irmanam por si mesmos para a realização de nosso conhecimento, como se um tivesse origem no outro, ou ambos em um tronco comum”. (Anth, § 31, p. 177).

As duas passagens remetem a uma ideia de unidade e de relação de reciprocidade entre as faculdades. Nesse contexto, para a faculdade de julgar reflexionante (estética, portanto), o Gemüt, como conceito unificador, assume importância fundamental por representar um todo vivido e não dado, a possibilidade de uma escolha de um modo universalmente válido, embora com a consciência de que a representação da experiência estética é referida ao sujeito em relação ao sentimento de vida ${ }^{16}$ ou de prazer/desprazer.

O sentimento de prazer poderia estar desconectado do conhecimento, entretanto, em dois momentos, pode se notar a profunda afinidade ${ }^{17}$ :

a) primeiro, na passagem que diz que já não sentimos prazer ao conhecermos a natureza e suas divisões a partir das suas leis particulares, embora entenda que esse prazer já existiu e foi gradualmente deixando de ser notado (KU, XL);

b) também na Antropologia, ao comparar a expressão sabor (sapor) com saber, diz que a primeira foi sendo elevada até passar a denominar a sabedoria (sapientia), inferindo que um fim incondicionalmente necessário surge imediatamente ao espírito como que pelo sabor, estando-se autorizado a partir de Kant a dizer que o saber tem sabor. (Anth, $\S 67$, p. 243).

\footnotetext{
${ }^{16}$ Sobre o sentimento de vida e a identidade deste com o sentimento de prazer próprio do juízo estético, a Reflexão 4857, datada de 1776-78 traz: "Unicamente prazer e desprazer constituem o absoluto, porque eles são a própria vida".

${ }^{17}$ Cita-se Kant: Entendo por afinidade a unificação que faz o diverso derivar de um fundamento (Anth, § 31, p. 177) [Ich verstehe unter der Verwandschaft die Vereinigung aus der Abstammund des Mannigfaltigen von einem Grunde].

CONPEDI LAW REVIEW | EVENTO VIRTUAL | v. 7 | n. 2 | p. 76 - 96 | JUL - DEZ | 2021 
Acerca do sentimento de vida e de sua capacidade unificadora, vale citar Rohden, V. (2009, p. 12, grifo do autor) interpretando a terceira crítica quando diz:

O sentimento de vida é um sentimento concernente ao todo, ao todo do mundo em que vivemos, é um sentir-se bem no todo do mundo ou em relação a um todo humano. [...] Gemüt significa então o todo das faculdades representativas. Então o importante nisso é que o sentimento estético e o juízo estético remetem a um todo vivido.

O universal não dado a priori pelo conceito é transcendentalmente possível pelo princípio transcendental da conformidade a fins, que será objeto de tratamento específico na sequência do trabalho, mas que já pode ser anunciado pela citação de Höffe:

Enquanto os fenômenos deixam constatar-se empiricamente (eles formam o particular dado), a suposição da totalidade conforme a fins não surge da experiência. A totalidade conforme a fins é o universal não dado, que a faculdade de julgar descobre por espontaneidade própria. Assim em juízos de conformidade a fins, o dar-se sensível, a natureza e o ato de pôr espontâneo, a liberdade, formam uma unidade originária. (HÖFFE, 2005, p. 295).

Nessa perspectiva, afirmará Rohden - com o que se concorda integralmente - que o sistema kantiano das três críticas forma

[...] um todo articulado como um organismo [...] a $\mathrm{KrV}$ pode ser entendida transcendentalmente na perspectiva do Gemüt como Ge-müt, ou seja, como um todo de faculdades em relação recíproca, sob o primado da razão e sob a mediação do juízo. (ROHDEN, V., 2009, p. 13).

Conill Sancho (2010, p. 24) acentua que entre as três faculdades existe "um nexo vital, uma unidade que brota do mundo da vida", entendendo, a partir da análise da ideia de vida na terceira crítica, que o sentimento de vida proporciona uma nova perspectiva para interpretar as funções reflexionantes da imaginação, afirmando que a interpretação nessa perspectiva se faz hermenêutica, porque as partes de um todo ${ }^{18}$ dado são usadas para enriquecer e especificar a nossa compreensão inicial. (CONILL SANCHO, 2010, p. 25-26).

Desse modo, com o princípio da conformidade a fins, o esquematismo kantiano passa a adquirir uma perspectiva de abordagem hermenêutica e ética, dado que a finalidade possui

18 No plano epistemológico, a concepção de Conill Sancho traz uma definição do modelo da integridade na hermenêutica dworkiniana (a questão da integridade será objeto de análise na segunda parte do trabalho). 
uma relação com a externalidade na qual os fins se realizam e constituem o lugar de significação da faculdade de julgar (que é estética na origem, mas encontra a ética e a cognição).

Mendonça (2007, f. 127-134), analisando o pensamento Simone Goyard Fabre, afirma que é a terceira crítica que permitirá que se dê um passo decisivo para a problematização do Direito a partir de Kant, pois o juízo estético é aquele que revela a intersubjetividade, estando no ato de julgar a elevação de um sentimento particular a um valor universal. Percebe que o juízo estético é fundamentalmente "para o outro", uma verdade para todos os sujeitos que parte de uma vivência pessoal. Ira dizer que a essência do sujeito que se manifesta no juízo estético é o que se poderia denominar de um "cogito plural".

$\mathrm{Na}$ edição francesa da terceira crítica, Mendonça (2007, p. 127-134) aponta que a forma de comunicação aberta pelos juízos reflexionantes na terceira crítica vincula tal crítica com as demais e reafirma o caráter sistemático do pensamento kantiano. Colhendo as constatações de Philonenko na edição francesa da Crítica da faculdade de julgar, aponta para o fato de a estética carregar a ideia de significação necessariamente jungida à ideia de comunicação, numa espécie de abertura que permite o encontro dos humanos. Conclui que é como lógica do sentido que a Crítica da faculdade de julgar pode se desenvolver como estética e teleologia, a primeira como a parte que contem a reflexão sobre a experiência da comunicação e a segunda como o encontro significativo do homem e do mundo. A teleologia esclarecerá o status da comunidade humana como comunidade de sentidos no mundo, cabendo à estética unir o universal e o particular, unificando intersubjetivamente o sistema kantiano e indo além do que ficou separado por toda tradição da metafísica ${ }^{19}$ (Philonenko chama de "ligação horizontal" a comunicação estética que liga o universal e o particular pela intersubjetividade).

As conclusões de Mendonça são coerentes com a posição de Connil Sancho (2010, p. 21), para quem a capacidade reflexionante possui uma função interpretadora e orientadora, estando o sujeito mais livre e permitindo que a imaginação organize a experiência num contexto interpretativo mais amplo.

Por fim, assim como o Gemüt representa uma unidade das faculdades no sujeito, com as considerações da tese de Mendonça, articula-se uma abertura ao outro a partir da terceira crítica, aspecto que será importante para o trato do processo intersubjetivo e da congruência

\footnotetext{
${ }^{19}$ A ligação horizontal que a estética permite irá se concretizar na concepção de coerência em Dworkin, objeto de análise em trabalhos futuros. 
entre as dimensões individual e universal, essenciais a uma defesa de uma hermenêutica desde Kant.

\section{O SENSUS COMMUNIS E O COMPARTILHAMENTO}

Na KU (§§ 39 e 40) Kant irá tratar de outra questão de suma importância para que a hermenêutica que ora se postula possa ultrapassar a subjetividade e ingressar no campo do compartilhamento, qual seja: a possibilidade de comunicar uma sensação e a pressuposição de um sensus communis.

Defende a possibilidade de comunicação entre sujeitos de uma sensação não reduzível a um conceito, ou seja, o prazer do belo é um prazer da reflexão inerente a um procedimento da faculdade do juízo que - partindo da apreensão pela intuição - eleva o intuído pela imaginação e pelo reflexionamento, entendendo Kant que este prazer necessariamente tem que assentar sobre as mesmas condições da possibilidade de um conhecimento em geral, em situação análoga ao que ocorre com as sínteses do entendimento puro (KU, AA § 39). Ainda, defende a necessidade de tal comunicação universal como a necessidade do próprio alargamento do conhecimento, afirmando que "[...] sem esta condição subjetiva do conhecer, o conhecimento como efeito não poderia surgir.” (KU, AA $\S 21$, p. 66).

A possibilidade de comunicação intersubjetiva do juízo do gosto também será defendida por Kant a partir da ideia de sensus communis que entende como a ideia de um sentido comunitário (gemeinschaptlichen), isto é, de uma faculdade de julgamento que na sua reflexão considera em pensamento (a priori) o modo de representação de todo o outro, uma condição dada pela capacidade empática da reflexão kantiana (alargamento do "eu" ao "nós") rigorosamente definida na terceira crítica $(\mathrm{KU}, \S 40)$.

A dificuldade da demonstração do juízo em face da ausência de uma regra que o demonstre de forma irrefutável, vai encontrar em Conill Sancho uma defesa da sua condição pragmática, quando assinala que [...] a capacidade do juízo não pode ensinar-se, senão somente exercer-se, exercitar-se, o que se assemelha - a meu modo de ver - a experiência, que não se aprende com princípios e regras, senão que consiste em exercer-se, praticar-se, realizar-se, viver-se. (CONILL SANCHO, 2010, p. 72). Com isso, o juízo estético, sem o aprisionamento dos conceitos, tangencia a experiência e deve estar na origem da orientação 
cognitiva, sendo algo compartilhado pela humanidade, a ponto de Conill Sancho (2010, p. 72) reconhecer que a capacidade de julgar caracteriza o sentido comum.

Kant apresenta as máximas que regem o sensus communis como uma espécie de entendimento humano comum ${ }^{20}$, que pode ser a condição de uma intersubjetividade possível, consubstanciado no "1. pensar por si, 2. pensar no lugar de todo o outro e 3. pensar sempre de acordo consigo próprio” (KU, §40). Makkreel irá dizer a partir de Kant (KU, §40, p. 160) que a primeira é a máxima do entendimento, a terceira da razão, sendo que a segunda interessa ao julgamento, comparando a nossa capacidade de julgar com a ideia de uma "razão coletiva da humanidade" (MAKKREEL, 1990, p. 159-160), requerendo que, ao julgar, a reflexão deva atingir um ponto de vista universal que somente é possível quando se está disposto a realizar a transposição do nosso ponto de vista para o ponto de vista dos outros, sem perder de vista a autonomia (pensar por si) e a responsabilidade do pensar consequente (pensar sempre de acordo consigo próprio).

A partir do sensus communis na terceira crítica, abre-se um espaço para que se possa pensar num campo pragmático transcendental, considerando a autonomia, a abertura ao diálogo e a responsabilidade, questões que possuem uma clara "função de orientação" pragmática, de compartilhamento de sentidos, permitindo que a construção a partir do juízo reflexionante encontre uma possibilidade de universalização. (MAKKREEL, 1990, p. 164). Permite-se, então, concluir que com o sensus communis há uma abertura de espaço para que a racionalidade hermenêutica se instaure [i] sem a dominação do conceito e [ii] a partir do reflexionamento e sua exteriorização como linguagem.

Tal questão que aparece na terceira crítica é retomada por Makkreel e transportada para uma sustentação da racionalidade hermenêutica, especificamente quando trata da interpretação reflexiva nas ciências humanas (MAKKREEL, 1990, p. 166), unindo o sentimento de vida e o sensus communis como condição de uma orientação transcendental a partir do juízo estético direcionado a fins.

\section{CONCLUSÃO}

\footnotetext{
${ }^{20}$ Existem algumas questões que são de domínio comum da humanidade: justo /injusto, certo/errado, acima/abaixo, etc., funcionando como uma estrutura a espera de preenchimento substancial que - hermeneuticamente - somente pode ser construído argumentativamente sob a égide dos juízos reflexionantes. 
Decorre da pesquisa a constatação de que existem fortes argumentos para se postular uma ligação entre a hermenêutica e os juízos reflexionantes, e que desde Kant é possível identificar de uma forma muito peculiar esta questão.

Inobstante a estética não fornecer uma fundamentação transcendental, ela faz a ponte entre cognição e ética, entre razão teórica e razão prática. É como se o campo pragmático da ética permitisse o encontro entre o juízo do belo e do justo. A vivificação do belo e do justo se dá na experiência, no mundo da vida, integrando o modo de ser hermenêutico apresentado a partir dos pressupostos kantianos.

Por isso é possível inferir que não tem sentido falar de uma hermenêutica sem o momento experiencial, sem a faticidade, dado que a unidade que permite o julgamento necessita ser vivificada. Tal necessidade impõe dizer que a hermenêutica desde Kant:

a) não é um procedimento rígido atrelado a um método causal;

b) não é dependente de uma descrição prévia de seus ritos, caracterizando-se por um processo que se legitima a posteriori fruto da análise das razões que traçaram o caminho percorrido pela decisão;

c) não é previamente normativa (tampouco contranormativa), no sentido de que regras da razão são observadas;

d) como se demonstrou, há uma legitimação filosófica (cognitiva, ética e estética) que permite a sua utilização na formulação de juízos no campo dos deveres.

Pode-se dizer que o Direito possui um valor estético que exige o cotejo da norma (obra cultural humana) com a vida. Uma hermenêutica crítica é um modo de refletir que privilegia o conhecimento da obra a partir da vida. A estética mostra que a partir da relação com o mundo há a internalização do sentimento (belo) que antes da assunção do comando de regras pela razão já carrega uma limitação do possível (uma orientação) para a tomada de decisão ou para atribuição de sentidos a partir de conceitos. Desde Kant pode-se dizer que uma teoria da orientação possui uma anterioridade "simbólica" e "existencial" a qualquer processo de decisão.

A hermenêutica crítica se constitui como um pêndulo que oscila entre a faticidade e a estética, sem esquecer que representa o tempo de um ser histórico envolto pelos conflitos inerentes a sua condição humana. Com o juízo reflexionante, há a compreensão de uma finalidade posta no mundo pela lei moral e de que, no direito, a hermenêutica encontra a sua objetivação no plano fático. Nesse sentido, a hermenêutica consiste no jogo de aproximação 
entre o sensível (apreensão das virtudes que circulam em sociedade) e o suprassensível (imperativo e o princípio do direito), tendo como mote a decisão que preserve o valor da moralidade aplicada (senso de realizar o bem).

Entende-se como virtude uma aparição da lei moral compartilhada intersubjetivamente, permitindo o acordo ou desacordo sobre certos atos, sendo a experiência o lugar do encontro do comportamento virtuoso. Nesse sentido, além da liberdade ser o antecedente dos deveres (ético e jurídico), a investigação abre-se a uma pragmática da liberdade e uma estética da liberdade em que a proposta de uma hermenêutica crítica se constitui.

Desde a estética kantiana não é possível afastar a subjetividade da justificação dos juízos, permanecendo como uma marca da hermenêutica que não se apaga em suas múltiplas manifestações. O caráter intersubjetivo e a comunicabilidade é que podem garantir a validação pela comunidade, num polo de captura da objetividade possível construída hermeneuticamente.

\section{REFERÊNCIAS}

ABBAGNANO, Nicola. Dicionário de filosofia. Tradução de Alfredo Bosi. 6. ed. São Paulo: Martins Fontes, 2012.

ARISTÓTELES. Ética a Nicômaco. Tradução Edson Bini. 3. ed. São Paulo: Edipro, 2009.

AUDI, Robert. Conhecimento moral e pluralismo ético. In Greco, J.; SOSA, F. (Orgs.). Compendio e epistemologia. São Paulo: Loyola, 2008.

CONILL SANCHO, Jesús. Ética hermenéutica: crítica desde la facticidad. Madrid: Editorial Tecnos, 2010.

DILTHEY, Wilhelm. A construção do mundo histórico nas ciências humanas Tradução de Marco Casanova. São Paulo: Ed. UNESP, 2010.

ECO, Umberto. Kant si ornitorincul. Traducere de Stefania Mincu. Constanta: Pontica, 2002.

GADAMER, Hans-Georg. Entre fenomenologia e dialética: tentativa de uma autocrítica. In: GADAMER, Hans-Georg. Verdade e método II. Petrópolis: Vozes, 2011.

GADAMER, Hans-Georg. Entre fenomenologia e dialética: tentativa de uma autocrítica. In: GADAMER, Hans-Georg. Verdade e método I. Petrópolis: Vozes, 2012. 
HAHN, Alexandre. A função da antropologia moral na filosofia prática de Kant. 2010. 245 f. Tese (Doutorado em Filosofia) - Instituto de Filosofia e Ciências Humanas, Universidade Federal do Rio de Janeiro, Universidade Estadual de Campinas, Campinas, SP, 2010.

HAMM, Christian. A hermenêutica da consciência estética. Anotações sobre a teoria de Gadamer. In: REIS, Róbson Ramos dos; ROCHA, Ronai Pires da (Org.). Filosofia hermenêutica. Santa Maria: Ed. da UFSM, 2000.

HEIDEGGER, Martin. Ser e tempo. Tradução Fausto Castilho. Campinas: Ed. Unicamp, 2012 .

HÖFFE, Otfried. Immanuel Kant. São Paulo: Martins Fontes, 2005.

HÖFFE, Otfried. Kant: crítica da razão pura: os fundamentos da filosofia moderna = Kants: Kritik Der Reinen Vernunft: die Grundlegung der modernen Philosophie, Tradução de Roberto Hofmeister Pich. São Paulo: Loyola, 2013.

KANT, Immanuel. Anthropologie du point de vue pragmatique. Paris: Flammarion, 1993.

KANT, Immanuel. Crítica da faculdade do juízo. 2. ed. Tradução de Valério Rohden e António Marques. Rio de Janeiro: Forense Universitária, 1995.

KANT, Immanuel. Crítica da razão prática. Tradução de Valerio Rohden. Ed. bilíngue. São Paulo: Martins Fontes, 2003.

KANT, Immanuel. Crítica da razão pura. Tradução de Manuela Pinto dos Santos e Alexandre Fradique Morujão. Tradução do original alemão intitulado Kritik Der Reinen Vernunft baseada na edição crítica de Raymund Schmidt, confrontada com a edição da Academia de Berlim e com a edição de Ernst Cassirer. Lisboa: Fundação Calouste Gulbenkian, 2001.

KANT, Immanuel. Fundamentação da metafísica dos costumes. Tradução de Guido Antônio de Almeida. Ed. bilíngue. São Paulo: Barcarolla, 2009.

KANT, Immanuel. La metafísica de las costumbres. Traduzido por Adela Cortina Orts y Jesus Conill Sancho. 3. ed. Madrid: Editorial Tecnos, 1999.

KANT, Immanuel. Prolegómenos a toda a metafísica futura $=$ Prolegomena zu einer jeden kiinftigen Metaphysik. Tradução de Artur Morão. Lisboa: Edições 70, 1988.

KANT, Immanuel. Que significa orientar-se no pensamento $?=$ Was heisst sich im Denken orientiren? In: KANT, Immanuel. A paz perpétua e outros opúsculos. Tradução de Artur Morão. Lisboa: Edições 70, 1993.

KANT, Immanuel. Eine Vorlesung über Ethik. G. Gerhardt (Ed.). Frankfurt Am Main: Fischer Taschembuch, 1990.

MAKKREEL, Rudolf A. Imagination and interpretation in Kant: the hermeneutical import of the Critique of judgment. Chicago: Chicago Press, 1994. 
MAKKREEL, Rudolf A. Orientation and judgment in hermeneutics. Chicago: Chicago Press, 2015.

MENDONÇA, Margarida Maria Seabra Prado. O direito na arquitetônica da razão pura: uma tentativa de fundamentação. 2007. Tese (Doutorado em Filosofia) - Programa de PósGraduação em Filosofia, Universidade Federal do Rio de Janeiro, Rio de Janeiro, RJ, 2007.

ROHDEN, Luiz. Hermenêutica filosófica: entre a linguagem da experiência e a experiência da linguagem. São Leopoldo: Ed. UNISINOS, 2002.

ROHDEN, Valerio. A função transcendental do Gemüt na Crítica da razão pura. Kriterion, Belo Horizonte, v. 50, n. 119, p. 7-22, jun. 2009. Disponível em:

<http://dx.doi.org/10.1590/S0100-512X2009000100001>. Acesso em: 23 fev. 2015.

SCHMIDT, Dennis J. On German and other Greeks: tragedy and ethical life. Indianapolis: Indiana University Press, 2001.

VAYSSE, Jean-Marie. Vocabulario de Immanuel Kant. Tradução Claudia Berliner. São Paulo: Martins Fontes, 2012. 